\title{
Implementasi Metode Ajar Interaktif dengan Augmented Reality untuk Mata Pelajaran Biologi
}

\author{
Intan Sari Areni ${ }^{1 *}$, Indrabayu $^{2}$, Wardi $^{1}$, Muh. Niswar ${ }^{2}$, A. Ais Prayogi ${ }^{2}$ \\ ${ }^{1}$ Departemen Teknik Elektro, Fakultas Teknik UNHAS \\ ${ }^{2}$ Departemen Teknik Informatika, Fakultas Teknik UNHAS \\ intan@unhas.ac.id*
}

\begin{abstract}
Abstrak
Pengabdian masyarakat dilaksanakan di SMP Negeri 1 Takalar ini bertujuan untuk memberikan wawasan baru bagi guru dan siswa terkait metode dan materi pembelajaran interaktif dengan Augmented Reality, yang diharapkan dapat meningkatkan motivasi belajar dan pemahaman siswa, khususnya mata pelajaran Biologi. Augmented Reality merupakan sebuah teknologi yang melibatkan overlay grafis komputer pada dunia nyata, dimana dunia maya tiga dimensi bisa dibawa ke lingkungan dunia nyata secara real-time. Augmented Reality merupakan salah satu teknologi yang dapat digunakan sebagai media pembelajaran. Sebagai media pembelajaran baru, maka diharapkan dapat menambah wawasan bagi para guru dan murid di SMP Negeri 1 Takalar. Selain itu, pengabdian masyarakat ini juga sebagai ajang sosialisasi hasil-hasil penelitian dari dosen dan mahasiswa pada Program Studi Teknik Elektro dan Teknik Informatika Universitas Hasanuddin. Pelaksanaan pengabdian pada masyarakat ini dibagi dalam 2 tahap, yaitu tahap sosialisasi metode pembelajaran dengan memanfaatkan teknologi Augmented Reality dengan smartphone dan tahap pelatihan penggunaan aplikasi edukasi sebagai hasil penelitian tim pengusul. Antusiasme dari kepala sekolah, guru dan siswa saat pelaksanaan kegiatan ini.
\end{abstract}

Kata Kunci: Augmented Reality; Pengabdian Masyarakat; Smartphone; Biologi; Rangka Manusia.

\section{Pendahuluan}

Kabupaten Takalar adalah sebuah daerah yang terletak di Provinsi Sulawesi Selatan dengan ibu kotanya terletak di Kecamatan Pattallassang. Daerah ini memiliki luas wilayah 566,51 $\mathrm{km}^{2}$ dengan jumlah penduduk sebanyak \pm 250.000 jiwa yang tersebar di 9 kecamatan, 22 kelurahan, dan 61 desa. Secara geografis, Kabupaten Takalar terletak antara 5 031' sampai $5^{\circ} 0381^{\prime}$ Lintang Selatan dan antara $1^{\circ} 9^{\circ} 0221^{\prime}$ sampai $199^{\circ} 0391^{\prime}$ Bujur Timur. Wilayah Kabupaten Takalar berbatasan dengan Kabupaten Gowa dari Utara, Selat Makassar dari Selatan, Laut Flores dari Barat, serta Kabupaten Jeneponto dan Kabupaten Gowa dari Timur. Sebagian dari wilayah Kabupaten Takalar merupakan daerah pesisir, yaitu sepanjang $74 \mathrm{~km}$ (Pokja Sanitasi, 2013). Di Kabupaten Takalar juga terkenal dengan sebuah tempat wisatanya untuk pendidikan lingkungan yang ramai didatangi berbagai lembaga pendidikan yang dikenal dengan nama Pusat Pendidikan Lingkungan Hidup (PPLH) Puntondo. Tempat ini menunjang upaya-upaya pengelolaan lingkungan melalui pendidikan yang partisipatif, informal, terbuka, dan santai (PPLH Puntondo, 2017).

Dalam rangka meningkatkan pembentukan etnis dan budaya lokal serta meningkatkan pola pendidikan masyarakat Kabupaten Takalar, pemerintah daerah telah membangun beberapa sarana pendidikan formal yang meliputi sekolah setingkat SD 247 buah, SMP 68 buah dan SMA 40 buah dengan rasio murid terhadap guru masing-masing untuk SD 11,73, SMP 10,64, dan SMA 9,52 (Pokja Sanitasi, 2013).

Sebagai tempat terselenggaranya proses belajar mengajar, salah satu tujuan dari sekolah adalah siswa mampu menyerap atau menguasai materi pelajaran yang disampaikan oleh guru secara tuntas. Salah satu sekolah yang merupakan SMP favorit di Kabupaten Takalar adalah Sekolah Menengah Pertama (SMP) Negeri 1 Takalar yang terletak di Jl. Tikolla Dg Leo Kecamatan Pattallassang. Setiap mata pelajaran yang diajarkan di sekolah ini memiliki tujuan-tujuan pembelajaran tertentu yang harus dicapai siswa, termasuk juga mata pelajaran 
IPA Terpadu. Sekolah ini memiliki jumlah siswa kelas 1-VII sebanyak 288 orang dan 7 orang guru IPA Terpadu. Di sekolah ini terdapat 1 Laboratorium IPA dengan alat peraga untuk bidang Biologi yang cukup lengkap dan 1 Laboratorium Komputer.

Pada kurikulum 2013, khususnya untuk tingkat SMP, terdapat beberapa perubahan pada pembelajaran Ilmu Pengetahuan Alam (IPA), diantaranya adalah konsep pembelajaran terpadu IPA (integrative science). Konsep keterpaduan ini ditunjukkan dalam Kompetensi Inti (KI) dan Kompetensi Dasar (KD) yakni dalam satu KD sudah memadukan konsepkonsep IPA dari bidang Biologi, Fisika, Kimia, dan Ilmu Pengetahuan Bumi dan Antariksa (Irma, 2015). Namun, khusus materi IPA Biologi, siswa lebih sering dihadapkan dengan konsep-konsep yang bersifat abstrak yang didominasi oleh istilah asing dan nama-nama ilmiah yang menyulitkan siswa dalam menghapal atau mengingatnya. Sehingga pelajaran IPA Biologi menjadi mata pelajaran yang dianggap sulit. Walaupun banyak siswa SMP Negeri 1 Takalar dapat memenuhi tujuan-tujuan yang diharapkan, namun ada juga beberapa yang tidak dapat memenuhinya. Tingkat penguasaan atau daya serap dan tingkat kerajinan siswa dalam menerima pelajaran yang bervariasi mempengaruhi hasil belajar yang dicapai. Selain itu, metode pembelajaran yang digunakan oleh guru juga masih bersifat konvensional tanpa melibatkan penggunaan teknologi.

Saat ini, pemanfaatan teknologi dalam menunjang proses pembelajaran semakin berkembang seiring dengan perkembangan teknologi, salah satunya adalah aplikasi android pada smartphone. Seperti pada penelitian Septri Elvrilla yang membuat aplikasi gerakan sholat berdasarkan buku teks belajar sholat menggunakan Augmented Reality agar mempermudah umat muslim ataupun para mualaf dalam mempelajari tata cara sholat yang benar dan tertib serta dapat meningkatkan kepahaman umat muslim dalam mempelajari tata cara sholat dengan mudah (S.Handri, 2015). Tentunya, jika pelajaran biologi dapat dibawakan dengan memanfaatkan teknologi tersebut, maka proses belajar mengajar di SMP Negeri 1 Takalar dapat lebih menarik dan memotivasi siswa untuk lebih berprestasi.

Oleh karena itu, kami dari tim peneliti Prodi Teknik Elektro dan Prodi Teknik Informatika bekerjasama membuat aplikasi berbasis android terkait metode dan materi pembelajaran dengan Augmented Reality yang dapat membantu proses pembelajaran IPA Biologi khususnya materi rangka manusia. Augmented Reality merupakan sebuah teknologi yang melibatkan overlay grafis komputer pada dunia nyata, dimana dunia maya tiga dimensi bisa dibawa ke lingkungan dunia nyata secara real-time (Abdul Hadi, 2017). Rangka (skelet) merupakan susunan tulang yang berkesinambungan, tidak dapat dilihat dari luar tubuh karena ditutupi oleh daging (otot) yang berperan melindungi organ dalam tubuh yang lunak. Jumlah pembentuk rangka manusia kurang lebih 206 ruas tulang. Rangkaian tulang-tulang inilah yang membuat manusia dapat berdiri tegak. Dengan teknologi Augmented Reality maka rangka-rangka manusia tersebut dapat terlihat nyata di smartpone. Hasil penelitian berupa aplikasi Augmented Reality rangka manusia tersebut akan diperkenalkan dan diajarkan melalui kegiatan sosialisasi dan pelatihan ke guru dan siswa SMP Negeri 1 Takalar yang merupakan mitra kami pada kegiatan Pengabdian pada Masyarakat ini.

Aplikasi pembelajaran yang dibuat diharapkan dapat memberikan wawasan baru bagi guru dan siswa di SMP Negeri 1 Takalar terkait metode dan materi pembelajaran, serta dapat meningkatkan motivasi belajar dan pemahaman siswa. Selain itu, pengabdian masyarakat ini juga sebagai ajang sosialisasi hasil-hasil penelitian pada prodi Teknik Elektro dan Prodi Teknik Informatika.

\section{Latar Belakang Teori}


Subjek pelaku dari proses kegiatan penggunaan aplikasi pada pembelajaran IPA Biologi adalah Siswa SMP Negeri 1 Takalar. Beberapa faktor yang sangat mempengaruhi hasil belajar siswa antara lain motivasi belajar dan keaktifan siswa dalam mengelola dan menerima pembelajaran yang telah diberikan Guru. Mata pelajaran IPA Terpadu yang di dalamnya sudah terdapat pelajaran bidang Biologi sudah diterapkan dalam lingkungan SMP Negeri 1 Takalar, akan tetapi motivasi belajar siswa masih perlu ditingkatkan lagi dengan memperkenalkan metode pembelajaran baru dengan memanfaatkan teknologi.

Secara garis besar, permasalahan pokok yang dihadapi oleh guru dan siswa di SMP Negeri 1 Takalar terhadap pengembangan pengetahuan IPA Biologi dijelaskan sebagai berikut:

(1) Metode proses belajar mengajar

Dalam proses belajar mengajar, guru hanya memberikan materi pelajaran IPA Biologi di dalam kelas tanpa penggunaan media teknologi, seperti komputer atau smartphone. Sehingga beberapa siswa kurang berminat dan sering sengaja tidak mengikuti proses belajar mengajar sehingga nilai yang didapatkan lebih rendah dari yang diharapkan. Selain itu, mata pelajaran IPA Biologi seharusnya diajarkan juga melalui kegiatan praktikum di laboratorium. Namun kegiatan praktikum mengalami kendala karena alat peraga yang ada terbatas.

(2) Pemanfaatan smartphone siswa

Sebagian besar siswa SMP Negeri 1 Takalar sudah mengenal dan menggunakan smartphone dalam kesehariannya. Sebagian besar siswa hanya menggunakan media ini untuk berkomunikasi, bermedia sosial dan game saja. Namun sebenarnya smartphone juga memiliki manfaat yang belum banyak digunakan oleh siswa dan guru yaitu sebagai media pembelajaran.

\subsection{Solusi yang ditawarkan}

Beberapa solusi yang ditawarkan sebagai usaha untuk memecahkan masalah yang dihadapi oleh guru dan siswa di SMP Negeri 1 Takalar dijelaskan sebagai berikut.

(1) Penambahan metode belajar efektif

Metode pembelajaran secara konvensional yang selama ini diterapkan guru belum mengatasi masalah minat dan semangat siswa yang rendah. Guru perlu menambahkan metode belajar efektif dengan memanfaatkan smartphone atau teknologi terbaru, sehingga pendalaman pelajaran biologi dapat dilakukan di rumah atau dimana pun siswa berada. Dengan bantuan teknologi, pembelajaran biologi pun dapat dibuat semenarik mungkin dalam bentuk Augmented Reality sehingga ada interaksi pelajar terhadap media pembelajarannya. Misalkan untuk materi Anatomi Tubuh Manusia yang membutuhkan tambahan alat peraga di laboratorium agar siswa dapat lebih memahami materi tersebut. Jika alat peraga konvesional dapat digantikan melalui Augmented Reality, guru tidak lagi sulit untuk mengajarkan kepada siswa bentuk dan sistem anatomi tubuh manusia yang seharusnya pelajar tahu dan keterbatasan alat peraga di Laboratorium pun akan teratasi.

(2) Minat dan kebutuhan pelajar terhadap peningkatan pemahaman IPA Biologi

Minat siswa dalam belajar IPA Bilogi di kalangan siswa SMP Negeri 1 Takalar masih rendah karena metode pembelajaran yang diterapkan guru tidak dapat menarik minat siswa dan pembelajaran di laboratorium jarang dilakukan. Untuk meningkatkan minat siswa dalam belajar IPA Biologi dapat dilakukan dengan pemanfaatan teknologi dalam hal ini smartphone sebagai media pembelajaran karena proses belajar mengajar akan menjadi lebih menarik. 


\section{Metode}

Usaha-usaha yang dapat dilakukan untuk memecahkan masalah yang dihadapi oleh masyarakat di Kabupaten Takalar khususnya di SMP Negeri 1 Takalar adalah dengan melakukan sosialisasi dan pelatihan bagi guru dan siswa di sekolah tersebut dengan uraian sebagai berikut:

(1) Melakukan sosialisasi tentang metode dan materi pembelajaran dengan memanfaatkan teknologi dalam hal ini smartphone khususnya untuk mata pelajaran IPA Biologi. Memperkenalkan bagaimana belajar IPA Biologi dengan lebih menyenangkan dan lebih mudah karena modul pembelajaran dikemas dalam bentuk aplikasi Augmented Reality.

(2) Melakukan pelatihan cara penggunaan Aplikasi Edukasi yang telah dibuat oleh tim pengabdian Prodi Teknik Elektro dan Prodi Teknik Informatika bagi para guru dan siswa di SMP Negeri 1 Takalar sebagai hasil penelitian tim pengusul.

\section{Hasil dan Diskusi}

Pada masa era teknologi informasi seperti sekarang ini, komputer memainkan peran yang semakin meningkat dalam berbagai bidang kehidupan manusia. Tidak dapat dipungkiri, peranan teknologi sangat berpengaruh pada bidang pendidikan khususnya sebagai media pembelajaran. Pada saat ini telah dikembangkan metode pembelajaran tiga dimensi untuk mempermudah proses pembelajaran, salah satunya Augmented Reality. Augmented Reality merupakan sebuah teknologi yang menghadirkan suatu integrasi informasi digital ke dalam lingkungan pengguna secara real-time. Berbeda dengan Virtual Reality (VR) yang menciptakan sebuah lingkungan artifisial, Augmented Reality menggunakan lingkungan nyata sekitar yang sudah ada, kemudian menambahkannya ke dalam informasi baru.

Rangka adalah susunan tulang-tulang dengan sistem tertentu. Rangka terletak dalam tubuh, terlindung atau terbalut oleh otot dan kulit. Rangka yang terdapat di dalam tubuh disebut dengan rangka dalam. Untuk mendukung fungsi gerak, selain didukung oleh kontraksi dan relaksasi otot, antara tulang dan ruas-ruas tulang satu dengan lainya dihubungkan oleh persendian tulang, pada persendian tersebut dilengkapi dengan tendon dan ligamenum. Interaksi dari seluruh komponen pendukung gerak tersebut akan menghasilkan gerak tertentu dari suatu organisme.

Spesifikasi minimum untuk menginstall aplikasi Augmented Reality Rangka Manusia yang dibuat ini adalah Android OS 4.0 Ice Cream Sandwich, Camera 2 MP dan Qualcomm Snapdragon 410.

Kegiatan Sosialisasi dan Pelatihan dalam rangka Pengabdian kepada masyarakat di SMP Negeri 1 Takalar telah dilaksanakan dan berjalan lancar karena dukungan dari pihak sekolah. Tampilan awal aplikasi diperlihatkan pada gambar 1 dan gambar 2 secara berurutan. Sedangkan gambar 3 memperlihatkan contoh tampilan aplikasi yang dibuat. 




Gambar 1. Tampilan awal aplikasi

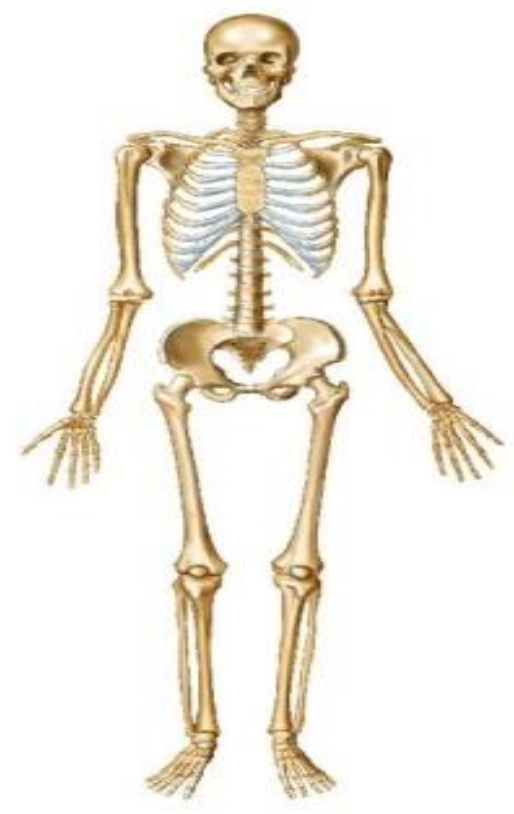

Gambar 2. Rangka manusia sebagai marker

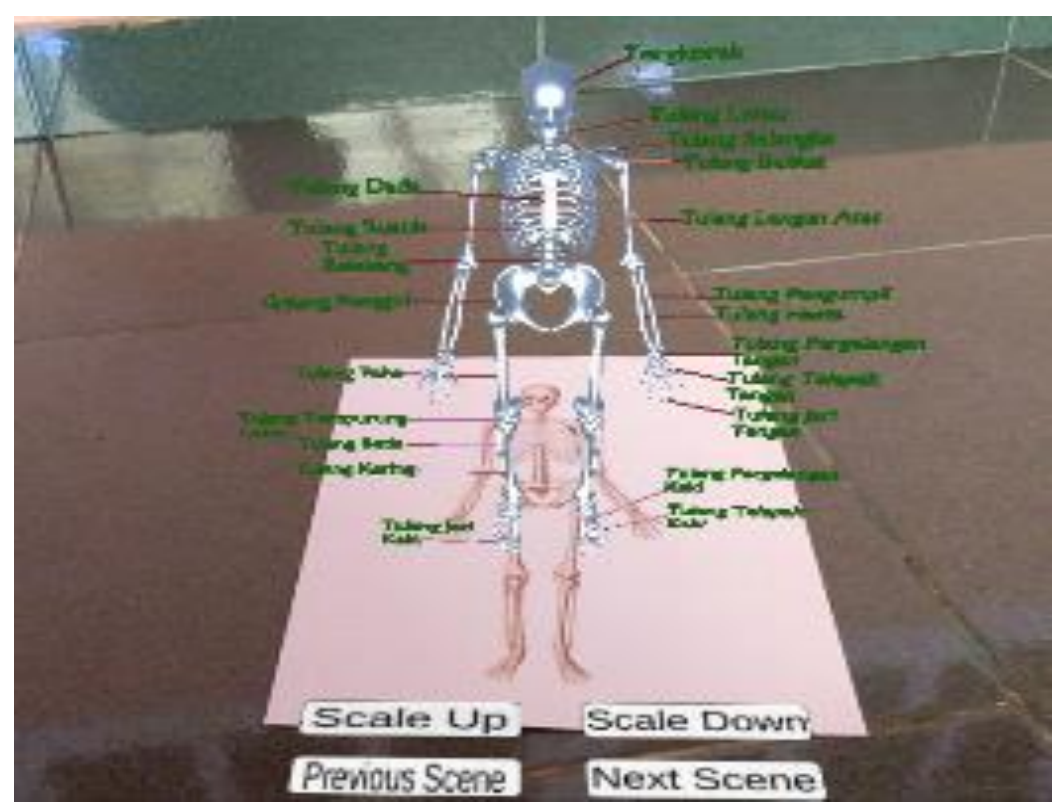

Gambar 3. Contoh tampilan pada smartphone 


\section{Kesimpulan}

Kegiatan pengabdian ini merupakan salah satu kegiatan untuk mensosialisasikan hasil-hasil penelitian yang telah dilakukan dan langsung dapat digunakan oleh masyarakat. Kegiatan ini terdiri atas 2 tahapan, yaitu Sosialisasi dan Pelatihan. Pada tahap sosialisasi diperkenalkan ke para guru tentang model pembelajaran interaktif dengan menggunakan smartphone dan teknologi Augmented Reality. Pelaksanaan kegiatan ini mendapat respon yang positif dari pihak mitra dan pihak sekolah sangat mengharapkan kegiatan seperti ini dapat sering dilakukan.

\section{Ucapan Terima Kasih}

Penulis mengucapkan terima kasih kepada mitra SMP Negeri 1 Takalar atas kerjasamanya dalam pelaksanaan kegiatan pengabdian ini. Selain itu, penulis juga mengucapkan terima kasih kepada Lembaga Penelitian dan Pengabdian Kepada Masyarakat (LPPM) Universitas Hasanuddin yang telah memberikan pembiayaan dalam bentuk hibah PPMU-PKM (Program Pengabdian kepada Masyarakat UNHAS - Program Kemitraan Masyarakat).

\section{Daftar Pustaka}

Abdul Hadi, R. P. (n.d.), (2017). Pengertian Fungsi Tulang Penyusun Kerangka Tubuh Manusia. Diakses di www.softilmu.com/2015/11/Pengertian-Fungsi-Tulang-PenyusunKerangka-Tubuh-Manusia-Adalah.html .

Elvrilla, S, (2011). Augmented Reality Panduan Belajar Sholat Berdasarkan Buku Teks Belajar Sholat Menggunakan Android.

Irma Muthiara Sari, Pedoman Mata Pelajaran IPA SMP, (2015). Diakses di www.slideshare.net/mobile/IrmaMuthiaraSari/pedoman-mata-pelajaran-ipa-smp .

Pokja Sanitasi Kab. Takalar (Buku Putih Sanitasi Kab. Takalar), (2013). Diakses di www.ppsp.nawasis.info/dokumen/perencanaan/sanitasi/pokja/bp/kab.takalar/buku .

PPLH Puntondo - Pusat Pendidikan Lingkungan Hidup Puntondo, (2015). Diakses di www.pplhpuntondo.or.id .

S. Handri Sunjaya, (2015). Teknologi Augmented Reality Berbasis Android Dalam Pembuatan Brosur Interaktif. 